\title{
Potential of Total Cycle Time Compression in Construction: Focus on Program Development and Design
}

\author{
Ralph Barker ${ }^{1}$; Paul Childerhouse ${ }^{2}$; Mohamed Naim³ ; Jan Masat ${ }^{4}$; and Derek Wilson ${ }^{5}$
}

\begin{abstract}
Time compression is a widely accepted approach to improving customer service levels while minimizing total costs. However, few applications within the construction sector exist, especially in relation to the early stages of program development and design. These stages are of paramount importance because of the resultant ramifications on the total cycle time of the entire construction project, in the form of changes, rework, waste, and risk. Most applications of time compression focus on quantifying and removing nonvalue adding time from business processes. This is difficult for program development and the design stages of construction because most information sources are qualitative. As a result, a methodology has been developed to identify the key areas of potential improvement during these early stages. Collection of opinion data via semistructured interviews, questionnaires, and a workshop with a cross section of supply chain members has made it possible to quantify the potential improvements. The action research findings have been summarized into a time-compression model for the program development stages in the format of two interlinked cause and effect diagrams. These further emphasize the need for effective program development to minimize the risks of project overrun.
\end{abstract}

DOI: 10.1061/(ASCE)0733-9364(2004)130:2(177)

CE Database subject headings: Time factors; Construction industry; Case reports; Construction management.

\section{Introduction}

The original contribution to knowledge by this paper is the development and implementation of a research methodology designed for identifying and quantifying time-compression opportunities in the program development stages of construction projects. Program development is the determination of client needs and project planning prior to developing a design. In some countries, particularly in the U.K., this stage of a project is referred to as briefing. The research is summarized in a time-compression model that illustrates the major factors in reducing total cycle time during these early and very important stages of a construction project.

\footnotetext{
${ }^{1}$ Senior Lecturer, Univ. of Glamorgan, Pontypridd, Mid Glamorgan CF37 1DL, UK. E-mail: rbarker@glam.ac.uk

${ }^{2}$ Lecturer, Management Systems, WMS, Waikato Univ., Private Bag 3105, Hamilton, New Zealand. E-mail: childerhousep@yahoo.co.nz; formerly, Research Associate, Logistics Systems Dynamics Group, Cardiff Univ.

${ }^{3}$ Reader, Logistics Systems Dynamics Group, Logistics and Operations Management, Business School, Cardiff Univ., Aberconway Building, Colum Dr., Cardiff CF10 3EU, UK. (corresponding author). E-mail: NaimMM@Cardiff.ac.uk

${ }^{4}$ Business Improvement Manager, Taylor Woodrow, Taywood House, 345 Ruislip Rd., Southall, Middlesex UB1 2QX, UK. E-mail: Jan.Masat@uk.taylorwoodrow.com

${ }^{5}$ Projects Director, Taylor Woodrow Construction Limited, 345 Ruislip Rd., Southall, Middlesex UB1 2QX, UK. E-mail: Derek.Wilson@uk.taylorwoodrow.com

Note. Discussion open until September 1, 2004. Separate discussions must be submitted for individual papers. To extend the closing date by one month, a written request must be filed with the ASCE Managing Editor. The manuscript for this paper was submitted for review and possible publication on December 21, 2001; approved on January 16, 2003. This paper is part of the Journal of Construction Engineering and Management, Vol. 130, No. 2, April 1, 2004. CASCE, ISSN 0733-9364/ 2004/2-177-187/\$18.00.
}

This paper reports on action research jointly sponsored by Taylor Woodrow Construction and the U.K. Department of Trade and Industry on time compression and risk management in the construction industry. The research is case based and has focused on a Private Finance Initiative (PFI) project. PFI is a new way of providing public construction projects in the U.K.; the aim is to assist in the integration of public and private sectors.

\section{Time Compression Principles}

The principles of time compression are not new. In fact, they can be traced back as far as the 16th century, during which time the Venetian assenalotti had successfully compressed the cycle time of war galley production to a single day (Towill et al. 2000). In the writers' opinions, the most influential modern day timecompression authors are Stalk and Hout (1990), Thomas (1990), and Towill (1996). The definition of total cycle time provided by these four authors is relatively similar. For this paper Thomas' definition will be used: "Total Cycle Time is the total elapsed time from the recognition of a need to fulfilling that need" (Thomas 1990). Stalk and Hout (1990) identify time compression as the new competitive weapon. They explain how the resultant strategic implications of compressing time are, "productivity increases, prices can be increased, risks are reduced and share is increased." As with Thomas (1990), Towill (1996) identifies the key drivers resulting from time compression as improved demand forecasting, quicker defect detection, and quicker to market; shortening of cycle time can have the largest single impact on a company's profitability. In the case of construction, virtually all business involves the design and development of new, customertailored products. The applicability and historical applications in the construction sector of Total Cycle Time (TCT) compression in the design and development of these new products is explained in the following section. 


\section{Time Compression in the Construction Sector}

Time compression in construction has often been realized as a potential force for competitive advantage within the different sectors of the industry (e.g., Chang 2001). However, with increasing client demands and awareness, especially of investment cycles and payback times, plus, in many cases, revenue generation of completed buildings and projects, the emphasis to reduce the cycle time has become even more evident. Construction for many years has been compared to other industries, particularly retail, electronics, and automotive, where the drive for innovation, overall efficiency, and cycle-time reduction has been revered as a target.

There are many instances where concentration on the actual construction process has produced savings in time and effort. The examples are Ibbs (1994), who looked at consolidation of work processes; Ireland (1996), where the number of contractors was rationalized; Waste (1999), reducing wastage of material and resources; and Doyle Wilson (Dougherty 1998), a house builder in Austin, Texas, who, through efficient planning and control, aims to quicken build cycle times. This latter example is similar to the construction of supermarkets and McDonald's restaurants, where time is very much of the essence. The application of time compression via a Just-in-Time (JIT) methodology has also been shown to give real benefits to construction, an example being Pheng and Tan (1998) and Pheng and Hui (1999) but, again, this is during the actual construction phase.

Elinwa and Joshua (2001) have highlighted a ranked list of causes for project overruns in Nigeria. Three of the top four variables directly related to the research conclusions described in this paper are improper planning, underestimation of time for projects, and frequent changes in design and materials.

Proper planning and adequate time estimation relate to the effective coordination of a project (de Saram and Ahmed 2001). They indicate that identifying strategic activities and potential delays are the most important factors leading to project overruns.

As more emphasis is placed on the total cycle time of construction, the greater the realization of the influence borne by the program development and design stages. Cooper (1998) shows the relationship of all phases of construction in a "process protocol map." It has been well known that the greatest potential for improvement in any project is at the concept and design stage, and the closer the project comes to actual construction the less beneficial are any possible ideas or changes. It therefore seems credible to argue that the stage before the design, that is, determining the clients' needs, has an even greater proportional ability to improve or put at risk the entire project. According to Jenks (1988), “inadequate briefing [program development] is probably the main reason why buildings have been wasteful of resources or defective in use." Consequently, with the aim of ensuring a better understanding of the "clients needs," much has been published on this initial stage of the construction process.

According to Barrett and Stanley (1999), in "1964 the Banwell Report stated that insufficient resources were devoted to defining project requirements and that this led to many problems in the construction processes thereafter. Thirty years later, the Latham (1994) report concluded that, amongst other things, more effort was required to understand clients' needs. Clearly the briefing [program development] process, or definition stage, is seen as both crucial to successful construction yet problematic in its effectiveness. Furthermore, this is a particularly intractable problem that does not seem to go away."

The problem appears to be that "program development" is not as simple as it may first appear. Classic publications such as New- man et al. (1981), Konya (1986), Parsloe (1990), Salisbury (1990), Construction Industry Board (1997), and O'Reilly (1997) all give good advice regarding program development for the construction industry, yet the problem is still apparent. Baldwin et al. (1999) state that conceptual and schematic stages of design will affect the whole process, and decisions made at this stage will have a major influence on overall project cost. This indicates that, although it should be obvious that correct program development is important, many companies are still not implementing the obvious.

Green and Simister (1999) have looked at Soft Systems Methodology (SSM) for strategic program development and state that in order to understand the client's needs properly it may be necessary to comprehend their business process. Bowen et al. (1999), in a South African survey of 373 construction industrialists, found that only " $40 \%$ of respondents believe that formal requirementselicitation procedures are used at most only infrequently" and that " $40 \%$ of all respondents claimed that inadequate briefing [program development] frequently or always results in client dissatisfaction with their building." There was also a perception gap between clients and other team members concerning communication set up by the client; on average, nearly $20 \%$ fewer "clients" than "all" respondents thought communication methods had been established.

Bresnen and Haslam (1991), presenting research on construction clients and their attributes and practices, showed that in a survey of 138 clients twice as many were dissatisfied with the time taken $(22 \%)$ than with the overall cost (11\%). They also found that client availability throughout the project was a major problem.

\section{Research Methodology}

The methodology is based on action research undertaken during an ongoing construction project that was still at the design stage. The project management team was concerned about disruptions that could lead to project overrun. The authors acted as a task force to identify the reasons, specifically the root causes, for any potential delays such as design changes and resource wastage. The methodology adopted is based on the proven timecompression process developed by Watson (1994) and as implemented by the Texas house builder Doyle Wilson (Towill 1997).

The methodology may be summarized as four major stages: Understand, Document, Simplify, and Optimize (UDSO). Once the specific business or construction process has been identified (which in this case is the program development and design process), the first stage of the methodology is the development of a clear understanding of that process and its associated characteristics. Secondly, this understanding is documented to ensure a shared and agreed view of the processes under analysis. The third stage of simplification is key to the methodology. All models developed in the documentation stage are evaluated in order to identify the potential time-compression opportunities. The final stage of the UDSO methodology is to optimize. In the context of time compression, this is the point at which the opportunities resulting from the time compression are realized and implemented.

This paper highlights the understanding, documentation, and simplification stages. The optimize stage is beyond the scope of the paper, but some early progress toward implementation is highlighted later. The specifics of the action research methodology are illustrated in Fig. 1. Each stage will now be explained in detail. 


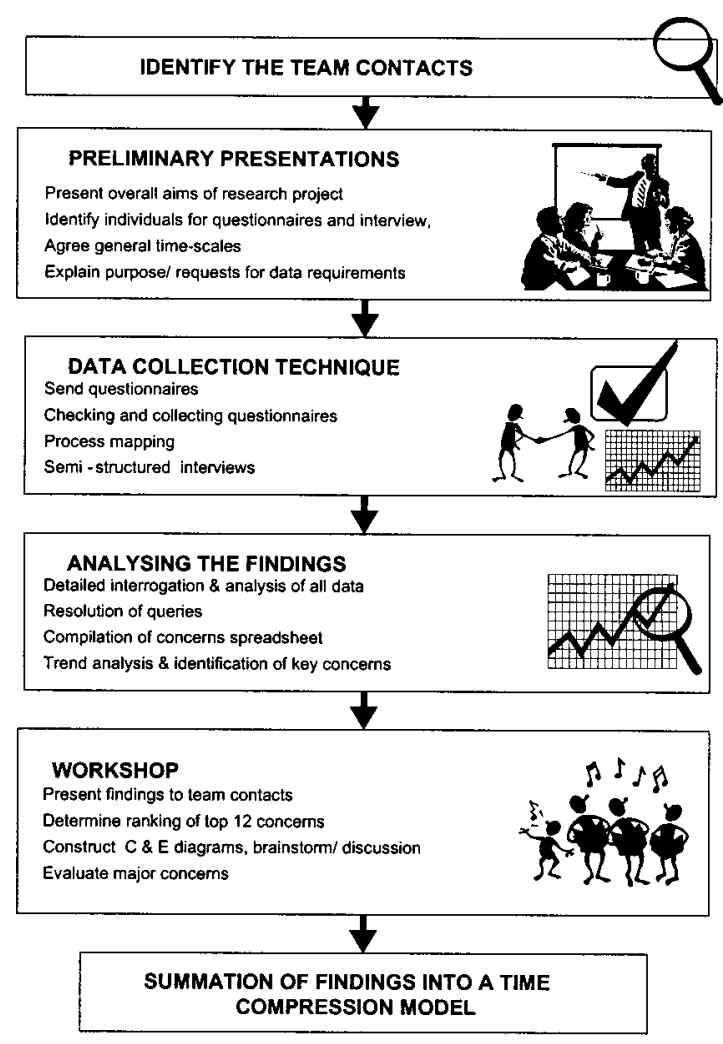

Fig. 1. Action research methodology

\section{Identify Team Contacts}

A list of all participants in the earlier stages of the project was created from preliminary discussions with selected Taylor Woodrow personnel. The list was used to group and select the main areas of influence. Individual names and titles were chosen that represented nine key functions, groups, or companies: architects, client (National Health Service), commercial manager, design manager, facilities management, health care adviser, mechanical and electrical services, project leader, and project manager.

\section{Preliminary Presentations}

Initially, a letter from the top management of Taylor Woodrow was circulated to all the main contacts stating the research goals and objectives. This was followed by preliminary presentations by the research team in order to ensure a clear and shared understanding of how the concepts of time compression in construction were to be investigated. Finally, the research team was introduced to each of the main contacts and schedules drawn up for the actual data-collection process.

\section{Data-Collection Technique}

It was decided first that independent data should be obtained from the different team contacts so as to reduce any bias or prejudice. In some cases a "team contact" could be an individual, or two or three people who represented a particular group or company. Questionnaires were prepared that asked about duties and responsibilities, communication methods, timing of involvement, procedures, problems, and general improvements. A range of closed, ranking, rating, and semi-open directed questions were employed based on the methods of Oppenheim (1992) and Saunders et al. (1997), as shown in the Appendix.

The questionnaire concluded with an open question on overall project improvement. These were followed with in-depth interviews that checked and triangulated the data obtained. During the interviews, process maps of each team contact's involvement in the project to date were drawn, with dates, activities, and key milestones. Because of the nature of the problems being investigated, the data collected were more qualitative than quantitative, and, where possible, two investigators attended each interview.

\section{Analyzing Findings}

Once all nine sets of team contacts had been seen, data analysis, understanding, and consolidation meetings were held with the research team. Here, key findings/concerns for each team contact were recorded. This resulted in a spreadsheet of all concerns against each team contact. Any queries, inconsistencies, or incomplete data at this stage were clarified by reference to the source. Through categorization, evaluation, and interpretation, the 12 most frequently occurring generalized concerns were identified (Table 1).

\section{Workshop}

The workshop was held to accomplish the following:

- To give feedback to participating team members.

- To validate and confirm the main findings from data collection.

- To analyze further data obtained, gather comments, and determine root causes of the most significant concerns.

The knowledge and experience of the project team's contacts and the current stage of the project formed an ideal situation for relevant information. A particular problem uncovered when planning the workshop was that it was felt by some industrialists that attendance by the client would somewhat restrict open debate and progress. Therefore, the client did not attend the workshop but was informed of the main findings.

Activities during the workshop can be summarized by the following:

1. Individual ranking of the top 12 concerns, done by $(a)$ greatest potential improvement to project (Table 1) and (b) greatest potential improvement to your organization (Table 1).

2. Team "cause and effect" diagrams of top three concerns as in $1 a$ above.

3. Brainstorming based on a quasi-Delphi study asking the participants to project forward to an ideal "perfect world" situation (Hong-Minh et al. 2001).

4. Team discussion of general concerns.

5. Determine individual ratings of potential percentage savings for each "greatest potential improvement to project" (in 1a) above, if that activity was correctly implemented (Table 2).

The resultant 12 major areas of potential improvement emerging in the program development and design stages as identified during the interviews were used as the basis for the workshop. An initial questionnaire was completed by each of the workshop attendees, leading to the results given in Table 1. A Likert scale of one to four was used to prioritize the potential areas of improvement; a score of one represents little opportunity for improvement, whereas a score of four indicates a large potential improvement. Workshop attendees completed two identical questionnaires, one 
Table 1. Ranking Questionnaire Results, Sample Means of the Twelve Areas of Potential Improvement

\begin{tabular}{|c|c|c|}
\hline \multirow[b]{2}{*}{ Respondents used a $1-4$ Likert scale, $1=$ low, $4=$ high potential improvement } & \multicolumn{2}{|c|}{ Sample mean } \\
\hline & $\begin{array}{l}\text { Overall } \\
\text { project }\end{array}$ & $\begin{array}{c}\text { Own } \\
\text { organization }\end{array}$ \\
\hline Better understanding and communication of the program development process & 3.5 & 3.4 \\
\hline Clearly defined and agreed roles and responsibilities & 3.1 & 3.0 \\
\hline Availability of client resources to suit the agreed time scales & 3.0 & 2.6 \\
\hline Clearly defined deliverables and time scales & 3.0 & 3.0 \\
\hline Improved and timely buildability input to design & 2.9 & 1.5 \\
\hline Increased use of IT communications/document systems & 2.6 & 2.4 \\
\hline Availability of appropriate ancillary providers resources & 2.4 & 2.0 \\
\hline Improved team working/relationships & 2.1 & 3.0 \\
\hline Improved structure and management of meetings & 2.0 & 2.8 \\
\hline Complete employee requirements before preparing 1:50 drawings & 1.9 & 1.8 \\
\hline Regular assessment and review of appropriate performance measurements & 1.8 & 2.3 \\
\hline Collocation of the project team & 1.6 & 2.8 \\
\hline
\end{tabular}

Note: Analysis of variance for both their own organization and the project as a whole are statistically significant at the $95 \%$ level $(F$-stat $=2.87$ and 2.16$)$. This illustrates that there is no evidence to show the resultant order of the 12 major areas is invalid.

for their organization and one for the project as a whole. Although the sample was relatively small, Analysis of variance (ANOVA) tests for both their own organization and the project as a whole are statistically significant at the $95 \%$ level $(F$-stat $=2.87$ and 2.16). ANOVA is a statistically valid way of conducting multiple t-tests. Therefore, the $95 \%$ result highlights that the alternative mean values of each of the 12 areas of improvement are significantly different from one another. Further, this validates the resultant order of the mean values and thus indicates that there is no evidence to show that the order of the 12 major areas is invalid, i.e., the major area of potential improvement is better understanding and communication of the program development process, including the client, which holds true for both a participant's own organization and the overall project.

During the last hour of the workshop the questionnaire was repeated with one alteration. The respondents were asked to estimate the percentage of time that could be saved if each of the potential improvement areas was performed optimally. The results are provided in Table 2 for their own organization and the project as a whole. An ANOVA test was carried out after the data in Table
2 were standardized, giving each respondent an equal weighting. The results for both overall project and own organization are statistically significant at the $99.9 \%$ level $(F$-stat $=5.68$ and 3.55$)$. Therefore, the order of the potential improvements is valid, and a better understanding of the program development process is the major area of potential improvement for the overall project.

\section{Summation of Findings into Time-Compression Model for Construction}

During the workshop, cause and effect analysis was conducted on the three highest ranked improvement areas identified for the project as a whole, as illustrated in Table 1. This activity, combined with a brainstorming session, initiated a great deal of discussion and has been summarized into two cause and effect diagrams. The first is based around the major factors influencing the program development stage of construction and is illustrated in Fig. 2. The second represents the design stage and is provided in Fig. 3. It should be noted that the key interlinkages between the

Table 2. Potential Time Reduction Percentage Questionnaire Results, Sample Means of the Twelve Areas of Potential Improvement

\begin{tabular}{|c|c|c|}
\hline \multirow[b]{2}{*}{ Respondents estimated percentage of improvements if area was performed optimally } & \multicolumn{2}{|c|}{ Sample mean } \\
\hline & $\begin{array}{l}\text { Overall project } \\
(\%)\end{array}$ & $\begin{array}{c}\text { Own organization } \\
(\%)\end{array}$ \\
\hline Better understanding and communication of the program development process & 29 & 19 \\
\hline Clearly defined and agreed roles and responsibilities & 27 & 24 \\
\hline Availability of client resources to suit the agreed time scales & 25 & 22 \\
\hline Improved team working/relationships & 18 & 13 \\
\hline Increased use of IT communications/document systems & 17 & 20 \\
\hline Clearly defined deliverables and time scales & 16 & 13 \\
\hline Improved and timely buildability input to design & 16 & 18 \\
\hline Complete employee requirements before preparing the 1:50 drawings & 15 & 25 \\
\hline Improved structure and management of meetings & 13 & 13 \\
\hline Regular assessment and review of appropriate performance measurements & 9 & 8 \\
\hline Availability of appropriate ancillary providers resources & 9 & 13 \\
\hline Colocation of the project team & 5 & 5 \\
\hline
\end{tabular}

Note: Analysis of Variance after the data were standardized, i.e., giving each respondent an equal weighting. The data show the results for both overall project and own organization are statistically significant at the $99.9 \%$ level $(F$-stat $=5.68$ and 3.55). This illustrates that there is no evidence to show the resultant order of the 12 major areas is invalid. 


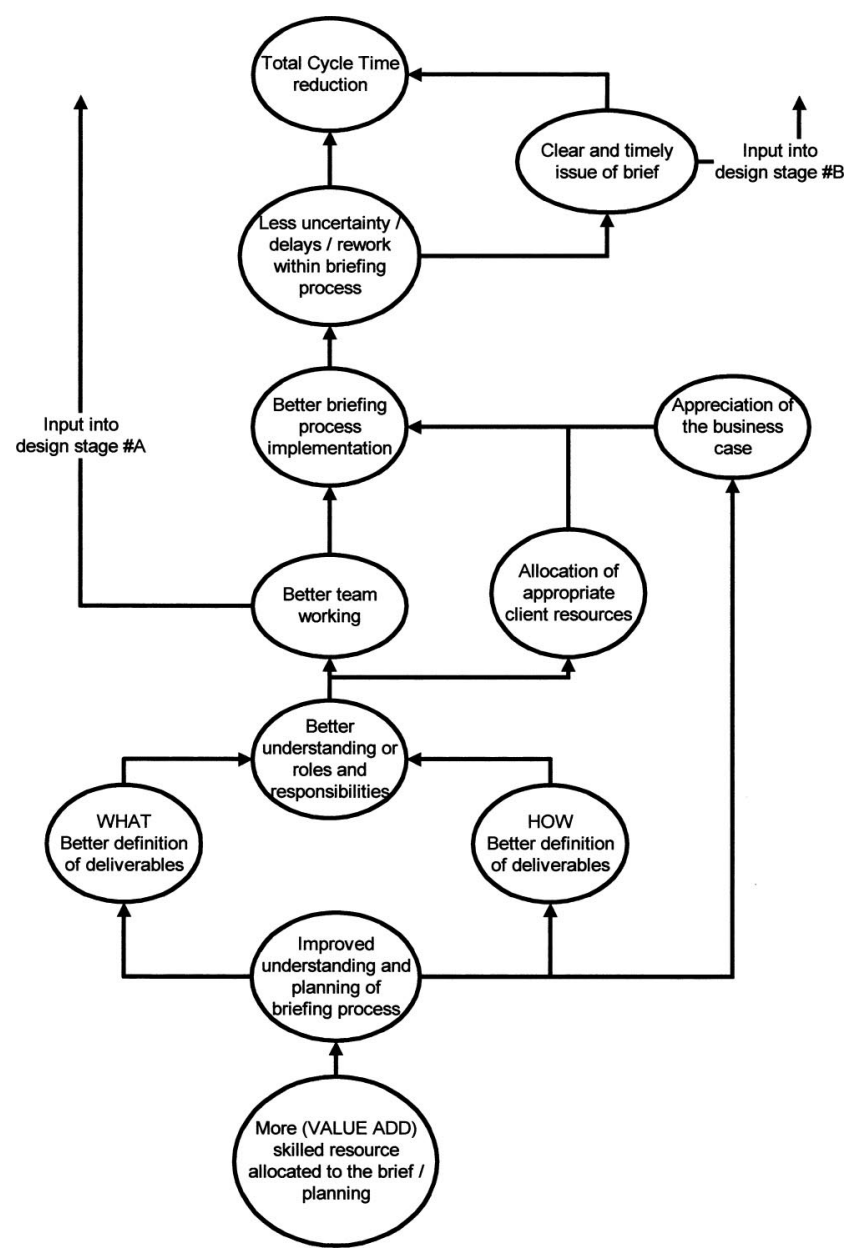

Fig. 2. Program development process cause and effect relationships

two stages have been highlighted. Both cause and effect diagrams have been developed to show the direct and indirect relationships between key issues of program development and design stages and total cycle-time compression.

\section{Discussion of Results}

This action research, as well as confirming widely held beliefs on the importance of program development and design stage, has yielded some very interesting results. The resulting cause and effect diagrams, in Figs. 2 and 3, show a great deal of similarity to the models developed by Barrett and Stanley (1999). They both emphasize the importance that correct program development and design have on the entirety of construction projects. Tables 1 and 2 further illustrate this point. Care must be taken in analyzing opinion-based data; however, it is clear that with such an experienced team, consensus is of value. Statistical analysis has also indicated the reliability of the consensus-based ranking.

The most important factor reported by the workshop attendees for the project as a whole is a better understanding and communication of the program development process to all parties, including the client. If this was performed optimally, the workshop attendees felt, on average, $29 \%$ of the overall project time could potentially be saved in comparison to the present situation. The percentage evaluations of feasible time compressions are very impressive (see Table 2); however, it should be noted that few of

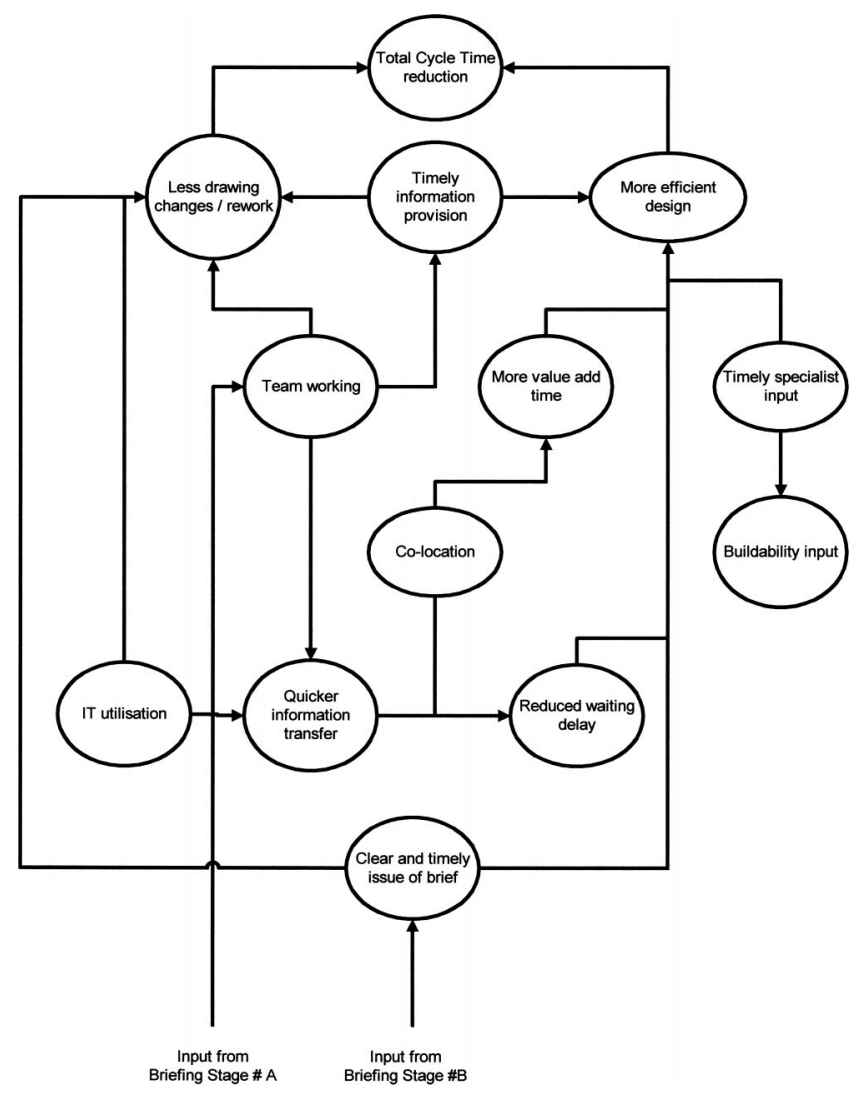

Fig. 3. Design process cause and effect relationships

the areas of potential improvement are mutually exclusive, so the cumulative saving cannot be calculated by summing all 12 percentages. For example, the increased use of IT overlaps with the advantages of collocation, because up-to-date information will be more readily available. This will also enhance team working and improve the interrelationships of the project team.

The second most important factor under "greatest improvement potential for the project as a whole" was "clearly defined and agreed roles and responsibilities," which again figures strongly in Barrett and Stanley (1999). This problem area is particularly important so as to minimize duplication and ensure key activities are performed on time by the most appropriate and skilled personnel. The third area for the project as a whole, with an estimated $25 \%$ feasible time reduction, is availability of appropriate client resources to suit the agreed timescales. This is a recurring issue for construction projects, with client education required due to their lack of experience in large one-off, or nonrepeated projects. As Bresnen and Haslam (1991) say, some clients are well-informed others are not, but their impact is significant.

The percentage improvements for own organization are somewhat different from the whole project, as illustrated in Table 2. In this instance, the highest, with $25 \%$ is complete employee requirements before preparing the 1:50 drawings. This is a major issue because a great deal of wasted time can be spent on rework and modifications if the 1:50 drawings are prepared before the exact client requirements are specified. The second and third highest areas are the same ranking for the overall project as they are for own organization.

One interesting point made by one of the workshop attendees is that the time will be compressed by around $10 \%$ even if nothing is done due to the effects of the learning curve, this was the 
Table 3. Program Development Process Improvements

Model elements

Improved understanding and planning of the program development process

Better definition of deliverables

Better understanding of roles and responsibilities

Appropriate allocation of end user/client resources
Improvements and their application

Develop an outline process map for Program Development at the commencement of the project. Hold a workshop-discuss, agree, and finalize a detailed program development process map for the project.

The program development workshop described above will improve understanding by the project participants, resulting in a realistic and credible program for the program development stage.

The process map will have identified the deliverables. These deliverables must then be defined in terms of the precise content and the level of detail required.

Roles and responsibilities should be clearly stated in relation to processes and deliverables. A matrix structure is recommended.

Having understood the process timescales, deliverables, and roles and responsibilities, the project team can then make a realistic assessment of required resources. If the required resources are not available, the plan must be reconsidered. The end user/client resources are key. first PFI project that any of the team had worked on. However, a different mix of personnel, which is likely, will negate this effect unless adequate organizational learning processes are in place. One important output of the workshop was the team's enhanced understanding of each other's perspectives and issues with the project.

\section{Recommendations}

The program development model and the design model (Figs. 2 and 3 respectively) were further developed to identify improvements in current processes that will enable time compression to be achieved. The method in which the models could be applied was discussed in workshops, and subsequent areas for application were identified. Not all elements of the model were developed; the concentration was on the elements that were seen as the root causes of problems. The model elements and the improvements proposed are summarized for program development and for design development in Tables 3 and 4.
The improvements described in Tables 3 and 4 are generic in nature. A similar approach applied to other projects is likely to identify further improvements specific to the nature of each project. The benefits of this method require only an improvement to existing practices as opposed to a substantial change to what is done. The actions required to achieve these improvements are clear, and the requisite tools are readily available. The key to success is the recognition of the benefits that will be accrued.

As mentioned in Table 4, the issue of collocation is a contentious subject. As seen in Tables 1 and 2, the participants ranked collocation very low. Research on the topic of collocation indicates considerable potential for improving communications between participants in a project. For example, Dahle (1954) showed that collocation is only $25 \%$ more effective than oral communication and $57 \%$ more effective than written communication.

Automotive companies have seen $25 \%$ faster development times for their product introduction via collocation. Suppliers involved in collocation exercises have achieved an annual average

Table 4. Design Process Improvements

\begin{tabular}{ll}
\hline Model elements & \multicolumn{1}{c}{ Improvements and their application } \\
\hline Collocation & $\begin{array}{l}\text { This was a contentious subject, where the possibility of bias occurred. It was reviewed in some } \\
\text { detail based on the frequency of communication that was reported between collocated and } \\
\text { noncollocated parts of the design team. It is a difficult principle to adopt partway through a } \\
\text { project, and, although the researchers believe there is great potential, further research it } \\
\text { needed. }\end{array}$
\end{tabular}

Improved use of available IT systems

Timely specialist/buildability input
Overall, it was considered by the team that the benefits of improved IT systems had not been fully evaluated. Tools are available from previous research, which enable selection, risk assessment, and the potential return on the investment to be measured. In the case study, these needed to be used in the early stages of the project.

Benefits of early involvement would be apparent with a clear process map, as it would "flag up" the implications related to the timing of selection. This has to be offset against the competitive pricing of components to deliver best value to the client. Cultural barriers also need to be addressed. 
improvement in their design and development performance of $10.3 \%$ compared to $7 \%$ performance for noncollocation suppliers (LRN 1999). It should be noted that the design and development phase for car manufacture is analogous with program development and the design phase of construction. Such a phase requires the bringing together of designers, manufacturers, assemblers, financiers, marketing, and sales personnel, i.e., bringing together different members of the product introduction project who would normally not be in the same physical location (Hong-Minh et al. 2001).

A number of specific issues have also been identified from the research

\section{Program Development Manager}

The successful management of the program development stage is of fundamental importance to the success of the overall project and warrants the appointment of a program development manager. This will clearly establish the responsibility for providing a robust program for the ongoing design development. It should be recognized that some initial design might be used to contribute to the definition of the program. Where this is the case, there should be a clearly recognized "gateway" through which the initial program design passes before it feeds into the ongoing design development process.

\section{New Project Participants}

When joining a new project, particularly when it is partway through, it can be difficult for new participants to quickly assimilate into the way the project operates. Process mapping, planning, definition of deliverables, and roles and responsibilities have the added benefit of aiding the rapid and effective integration of the new project participants. When reviewing our research work with some of the PFI team, it was mentioned that the process maps we had developed aided clarity and would certainly have been helpful to them during the project.

\section{Progressive Programming}

On some projects, it may be decided that the program will be defined in more detail as the design and possibly even as the construction develops. On such projects, greater discipline will be required to ensure that design is not developed ahead of the appropriate level of definition of the program. The progressive development of the program would be recognized in the outline program process map and would be fed into the development of the overall project plan.

\section{Exploitation and Benefits of Time Compression Approach in Taylor Woodrow}

\section{Exploitation in Design Teams on New Projects}

Implementation of the research findings and recommendations was crucial verification of the usefulness of the work. Taylor Woodrow initially focused on the development of process maps for the program development and design phases of new projects. This improved communication achieved a shared understanding of the process for identifying and documenting the client's requirements and transferring them into the development of the design. In relation to risk, this had the effect of correcting some misunderstandings, minimizing rework and reducing the uncertainty within the team.

Workshops on different projects were subsequently run by Taylor Woodrow that focused on developing a process map to define the logic sequences and then applying resources and program restraints to make the process map time-based. From this point, deliverables and responsibilities were identified and defined by weekly worksheets for each of the key participants.

Issues identified in the research were introduced to the new project's design team for debate in the forum of a workshop. One of the areas discussed was the consideration of a colocated design team. In this new project there were perceived to be considerable advantages in having a colocated team on site adjacent to the project. A number of user-group meetings were planned, and being colocated at the site was considered to offer advantages in terms of shared knowledge, productive working time rather than travelling time, and the development of a team culture.

The need for a committed client resource was discussed using the research findings. The research had considered the need to co-opt a member of the design team into the client organization to facilitate program development. It was recognized that this would need considerable work to enable the level of trust and the cultural change required. If this could be achieved, the program development process could be improved and the number of usergroup meetings reduced, leading to a reduction in time to complete the program development phase.

The output from the workshops run by Taylor Woodrow were then developed by the Project Manager, Planning Manager, Design Coordinator, and the Research Project Manager. A process map was produced using standard Microsoft Office software to enable it to be distributed electronically around the design team. The map indicated a "functional" rather than "process" project organization. It was also proposed that the project team should identify clearly the responsibilities between design team members.

\section{Applying Time Compression to Building Components}

As a trial, the time-compression method was applied to one element of a building project where there was a clear need to reduce time. This was the identification of a means to achieve an earlier watertight enclosure of the building envelope for another PFI Hospital project. This project was at a stage where program development and design processes could still be influenced by research findings.

This review was structured around the five program development and three design "areas for improvement" that were identified in Tables 1 and 2. The total cycle-time reduction opportunities that were identified were compared to these to find if they could be applied to a building component in the same way that they apply to the entire program development and design process.

A comprehensive review of the process in which the building envelope would be procured was undertaken. The focus was on the process without looking at the actual products that could be chosen to provide the building enclosure. This resulted in the identification of the following key time-improvement opportunities:

- Information Technology. There was recognition that adequate software protocols had to be used. Incompatibilities in software can mean errors in information transfer as well as generating human handling errors if diagrams have to be printed and redrawn. 

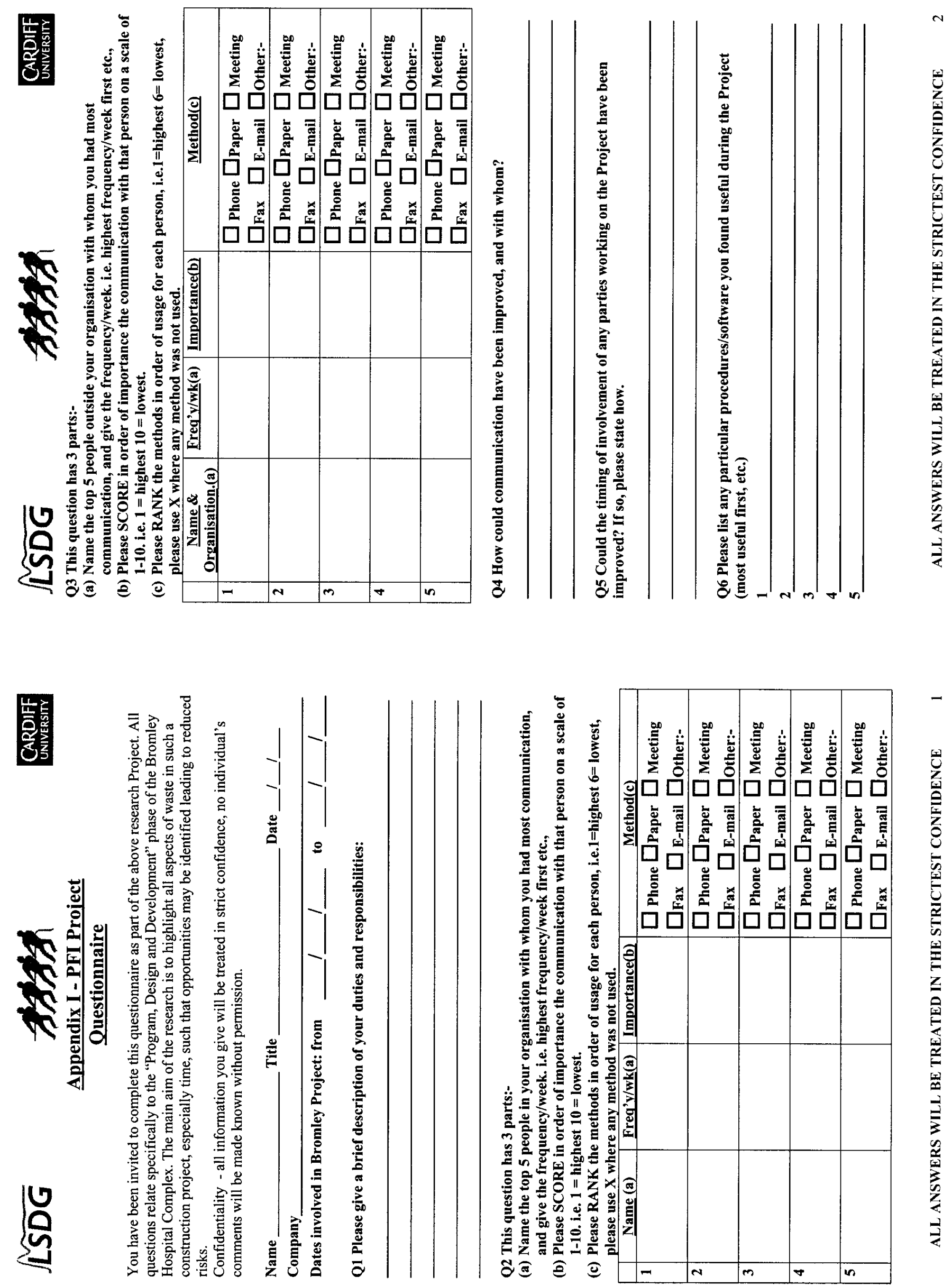

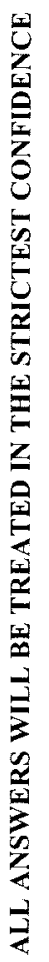



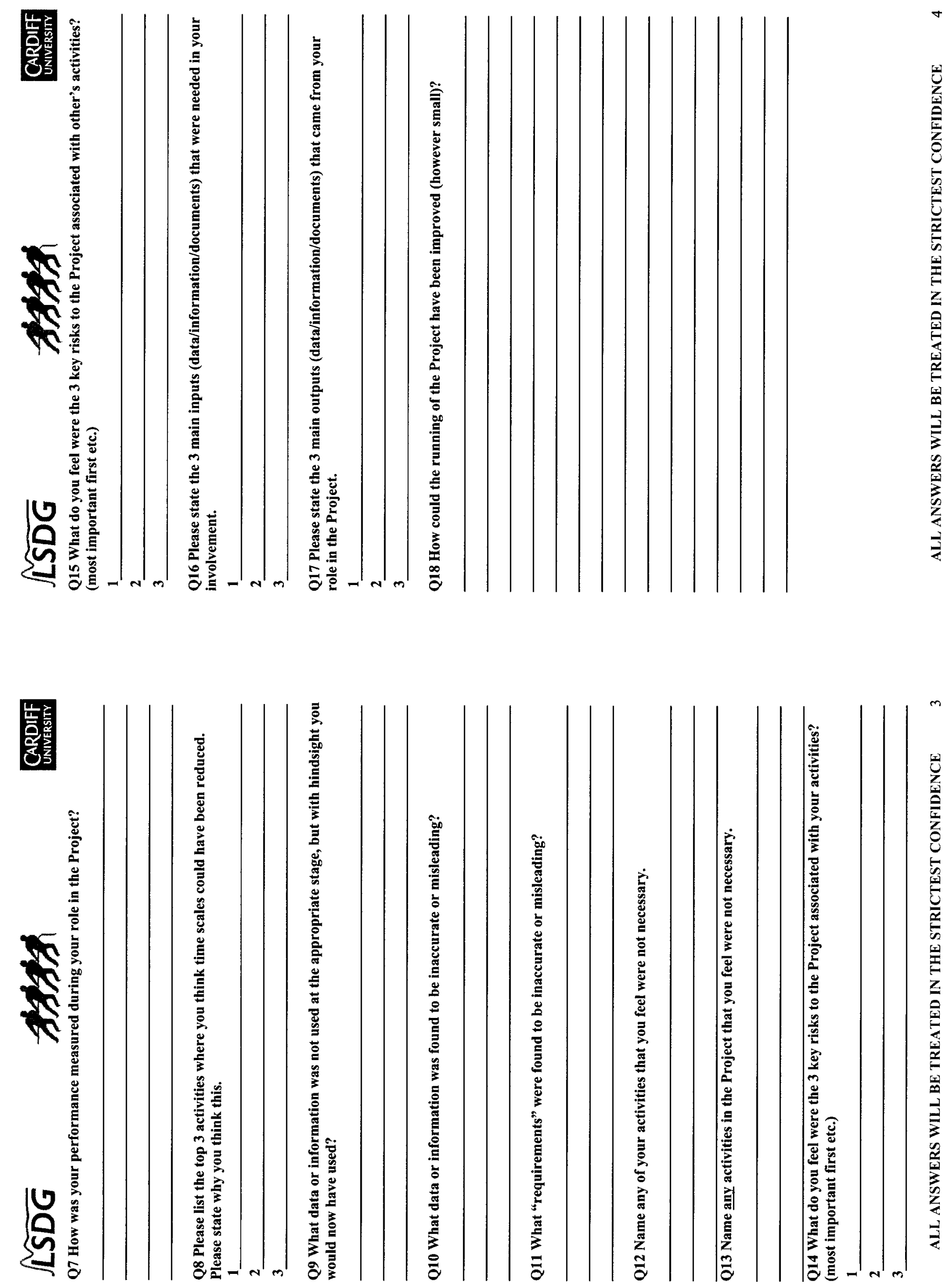
- Collocation. This particular project team put a lot of emphasis on the need to share "intellectual capital" to derive innovative methods of construction and use of new materials.

- Process Mapping. Particular attention was given to the development of a project process map at the program development phase that emphasized the interrelationship between activities and the roles and responsibilities of project team members. The process map was to act as an aid memoir for the project team and would be reviewed on an ongoing basis.

- Innovative Construction Methods or Materials. Innovative cladding erection systems were considered that had an increased handling element but could be compensated for by the use of robotics, leading to overall TCT compression.

\section{Benefits Recognized and Changes that Have Taken Place}

The potential benefits that were identified in the research are being realized in a number of new projects, specifically, the top five recommendations of the workshops. The reasons for this are that it is evident that the members of the project teams that have been involved in the research have understood and recognized the benefits and are applying the improvement recommendations.

Members of the project team who were included in the research interviews and workshops have bought into the recommendations and instigated these improvements in projects in which they have subsequently become involved. It is the view of the research team that this "buy-in" was achieved through the facilitation approach that was adopted for the research. The project team recognizes that their ideas will make the improvement, but it was time compression techniques that allowed them to identify the potential improvements.

\section{Conclusion}

This paper has presented research into time compression in the construction sector, with particular attention paid to the initial stages of program development and design. As with many other industrial sectors, time compression is an excellent methodology to improve effectiveness and increase competitiveness. Because of the qualitative nature of information during the program development and design stages, a specific methodology was developed. This proved very successful and provided valuable information for the development of a time-compression model. The workshop, the concluding part of the understanding and documentation stage, resulted in the prioritization of the previously established "shopping list" of feasible improvement areas.

Some impressive estimates of potential time compressions of up to $29 \%$ were established based on the participants' opinions. These further illustrate the use of time compression as a technique for improving performance. It should be noted that although the qualitative estimates for TCT compression given in the paper are specific to the research undertaken, the methodology developed to obtain the estimates and the resulting "lessons learned" are generic.

Although the estimates are opinion-based, they were developed by a group of experienced personnel who were actively involved in a construction project. Although the prioritized list of potential improvements areas seems obvious, it was not possible for the project team to discuss them without the facilitation provided by the adopted methodology, which allowed team members to communicate directly and obtain a shared understanding of the overall project process. Through this understanding, they realized the causal implication of their actions on the other team members and the project duration time as a whole. The methodology also enables a consensus to be formed as to the priorities of the team as a whole to ensure project schedule adherence.

\section{Acknowledgments}

The authors would like to thank the invaluable input from all those who were interviewed and attended the workshop for the PFI project. This research has been made possible by a jointly funded Taylor Woodrow, DTI Partners in Innovation Scheme: Reference 39/3/445 cc1548, titled "Using Time Compression in Construction to Reduce Risk." Thanks are also extended to the referees, who provided invaluable critiques, and to Mike Jones who helped with the terminology and grammar.

\section{Appendix.}

PFI Project questionnaire.

\section{References}

Baldwin, A. N., Austin, S. A., Hassan, T. M., and Thorpe, A. (1999). "Modelling information flow during the conceptual and schematic stages of building design." Constr. Manage. Econom., 17(2), 155167.

Barrett, P., and Stanley, C. (1999). Better construction briefing, Blackwell Science, Oxford, U.K.

Bowen, P. A., Pearl, R. G., and Edwards, P. J. (1999). "Client briefing processes and procurement method selection: A South African study." Eng., Constr., Archit. Manage., 6(2), 91-104.

Bresnen, M. J., and Haslam, C. O. (1991). "Construction industry clients: A survey of their attributes and project management practices." Constr. Manage. Econom., 9(4), 327-342.

Chang, A. S.-T. (2001). "Work-time model for engineers." J. Constr. Eng. Manage., 127(2), 163-172.

Construction Industry Board. (1997). Briefing the team: A guide to better briefing, Thomas Telford, London.

Cooper, R. (1998). The process protocol-Level two, EPSRC Construction as a Manufacturing Process Innovative Manufacturing Initiative, Univ. of Salford/Loughborough Univ.

Dahle, T. (1954). "Transmitting information to employees: A study of five methods." Personnel, 31, 243-246.

Dougherty, K. (1998). “Cycle time.” Builder 〈www.Builderonline.com〉 (May 1998).

Elinwa, A. U., and Joshua, M. (2001). "Time-overrun factors in Nigerian construction industry." J. Constr. Eng. Manage., 127(5), 419-425.

Green, S. D., and Simister, S. J. (1999). "Modelling client business processes as an aid to strategic briefing." Constr. Manage. Econom., $17(1), 63-76$.

Hong-Minh, S. M., Barker, R., and Naim, M. M. (2001). "Identifying supply chain solutions: Those suitable for the U.K. house building sector." Eur. J. Purchasing Supply Chain Manage., 6(4), 45-59.

Ibbs, C. W. (1994). "Re-engineering construction work processes." Int. J. Constr. Inf. Technol., 2(4), 27-47.

Ireland, V. (1996). "T40-Radical time reduction in construction projects." Business Change Re-eng., 3(1), 28-38.

Jenks, M. (1988). The briefing process-A critical examination, Chartered Institute of Building, King's Ride, Ascot, U.K.

Konya, A. (1986). Libraries: A briefing and design guide, Architectural Press Ltd., London.

Latham, Sir M. (1994). Constructing the team, HMSO, London. 
"LRN Automotive Supply Chain Re-Engineering Workshop." (1999). Logistics Focus, 7(4), 43-44.

Newman, R., Jenks, M., Bacon, V., and Dawson, S. (1981). "Brief formulation and the design of buildings." Report of the Dept. of Architecture, Oxford Polytechnic, Oxford, U.K.

Oppenheim, A. N. (1992). Questionnaire design, interviewing and attitude measurement, Printer Publishers, London.

O'Reilly, J. J. N. (1997). Better briefing means better building, Building Research Establishment, Garston, Watford, U.K.

Parsloe, C. (1990). Design briefing manual, BSRIA Publications, Bracknell, Berks, U.K.

Pheng, L. S., and Hui, M. S. (1999). "The application of JIT philosophy to construction." Constr. Manage. Econom., 17(5), 657-668.

Pheng, L. S., and Tan, S. K. L. (1998). "How just in time wastage can be qualified: Case study of a private condominium project." Constr. Manage. Econom., 16(6), 621-635.

Salisbury, F. (1990). Architect's handbook for client briefing, Butterworth's, London.

de Saram, D. D., and Ahmed, S. M. (2001). "Construction coordination activities: What is important and what consumes time." J. Manage. Eng., 17(4), 202-213.

Saunders, M. K., Lewis, L., and Thornhill, A. (1997). Research methods for business students, Pitman, London.

Stalk, G., and Hout, T. M. (1990). Competing against time, Collier Macmillan, New York.

Thomas, P. R. (1990). Competitiveness through total cycle time, McGraw-Hill, New York.

Towill, D. R. (1996). "Time compression and supply chain management." Logistics Information Management, 9(6), 41-53.

Towill, D. R. (1997). "Enabling construction as a manufacturing process." Proc., Mouchel Centenary Conference, Civic-Coup Press, Edinburgh, 145-152.

Towill, D. R., Childerhouse, P., and Disney, S. M. (2000). "Speeding up the progress curve towards effective supply chain management." Int. J. Supply Chain Manage., 5(3/4), 122-130.

"Waste audit and minimisation at Pegasus Court construction siteInterim report." (1999). CaliBRE, Garston, Watford.

Watson, G. H. (1994). Business systems engineering, Wiley, New York. 